\title{
Study of molecular evolution between plants and microbes
}

\author{
Durgude S.G. ${ }^{1}$, Maurya B.D. ${ }^{1}$, Pawar S.V. ${ }^{1}$, Chate P.B. ${ }^{2}$, Kayarkar N.A. ${ }^{1}$, Boraste A. ${ }^{3}$, Kadam P. ${ }^{3}$ and \\ Gomase V.S. ${ }^{4 \times}$ \\ ${ }^{1}$ V.E.S. College of Arts, Science and Commerce, Chembur, Mumbai-400 071, India \\ ${ }^{2}$ Bhavan's College, Andheri (west), Mumbai-400 058, India \\ ${ }^{3}$ Padmashree Dr. D.Y. Patil University, Navi Mumbai, 400614, India \\ ${ }^{4 \star}$ School of Technology, S.R.T.M. University, Sub-Centre, Latur, 413512, India
}

\begin{abstract}
In essence, every plant-microbe interaction is unique with the potential to yield novel information. Plants are members of complex communities and interact both with antagonists and beneficial organisms. The area of plant-microbe interactions is important because it addresses fundamental questions in biology while it also is of practical value for the application of beneficial microbes and the control of harmful pathogens in an environmentally responsible manner.
\end{abstract}

Key Words- Superficial Liaisons, Colonization, Ecology, Molecular Evolution, Metabolic Switches, Lateral Gene Transfer, Species Delineation, Biogeography

\section{Introduction}

Nutrients are essential to the survival of all organisms. As primary producers, higher plants represent the chief source of carbon and energy for a large number of creatures, ranging from microbes to humans. Some of these organisms have developed diverse and often complicated sensory mechanisms or organs that allow them to identify and locate the appropriate plantproduced nutrients. Symbiosis is phenomenon which involves the living together of unlike organisms. This term can be applied to a wide range of biological interactions. Mutualism, parasitism or commensalism are different symbiotic relationship exist in nature. More narrowly it can be defined, as only those relationships from which both organisms benefit, in which case it would be synonymous with mutualism. Ectosymbiosis is relationships which include those associations in which one organism lives on another whereas endosymbiosis is relationship where one partner lives inside the other. Symbiotic relationships may be either obligate or facultative. Obligate relationship is necessary for the survival of at least one of the organisms involved in association. Facultative relationship is beneficial but not essential for survival of organism. Molecular Mechanisms of Plant and Microbe Coexistence present studies on the complex and manifold interactions of plants and microbes at the population, genomics and proteomics level. Microbial communities are shown in the light of evolution. Main topics include Superficial Liaisons, Colonization, Ecology and Molecular Evolution, Metabolic Switches, Lateral Gene Transfer, Species Delineation and Biogeography, Molecular CoEvolution, which could form the basis for new environmentally benign strategies to combat infectious plant diseases and regulate plant growth. In this review we will describe the different step which leads to molecular evolution between plants and microbes. First step is superficial liaison which involves interaction of microbes with plant at surface. This interaction further leads to colonization of microbe to particular area on plant. Colonization further may results in metabolic switches, lateral gene transfer, species delineation and thus in molecular evolution. Many times microbes interact with plant but without genetic exchange, phenomenon called as molecular co-evolution. Ecology explains relations of organisms to one another and to their physical surroundings.

\section{Superficial Liaisons}

Microbes interact with plants initially at surface level through various interactions. The detection of host [plant]-released signals by members of the Rhizobiaceae \& Agrobactereceae and response to these signals is being intensively investigated. This a-proteobacteria include various plant symbionts, Rhizobium, Sinorhizobium, Mesorhizobium, Azorhizobium, and Bradyrhizobium, collectively called rhizobia, which fix atmospheric nitrogen and the plant pathogens Agrobacterium tumefaciens and $A$. rhizogenes, referred to as agrobacteria, which cause crown gall tumors and other neoplasias on a wide variety of plants $[1,2]$. Similarities exists between this two genera which include metabolic, transport, and regulatory systems that promote their survival in the competitive rhizosphere, whereas differences lie in genes specifically required for interaction with a plant host $[3,6]$. Genes responsible for interactions are carried on the tumor-inducing [Ti] plasmid in agrobacteria and on the symbiotic plasmids pSymA and pSymB in Sinorhizobium meliloti [6]. In Bradyrhizobium japonicum and Mesorhizobium loti, the symbiosis-related genes are carried on a chromosomally located symbiotic island [4, 5]. In chemo taxis plants exude high levels of nutrients, and many of these act as chemoattractants for the bacteria. The nutrients include sugars, amino acids, aromatic compound like acetosyringone, succinate, malate, catechol etc. which attract different strains of Rhizobia and Agrobacteria. [7, $8,9,10]$ Chemo taxis leads to binding of 
Rhizobia and Agro bacteria to plant surface which is essential for long-term interaction of the bacteria with their plant hosts. Several plant factors also found to be involved in this attachment. Plant lectins are proteins that possess at least one noncatalytic domain that binds reversibly to mono- or oligosaccharides, could serve as receptors for bacterial exopolysaccharides [EPS] [11, 12, and 13]. Binding of Rhizobia and Agrobacteria to plant surfaces is thought to take place in two steps [14]. The first binding step is weak and reversible. It involves a variety of bacterial polysaccharides which are the products of the ndvA and ndvB genes in Sinorhizobium meliloti and of the homologous chvA and chvB genes in $A$. tumefaciens. These genes are involved in the synthesis of a cyclic glucan [15, 16, 17], which could act as an adhesin via gelling interactions with host polysaccharides or could interact with plant lectins [11]. The second binding step requires the synthesis of bacterial cellulose, which causes a tight, irreversible binding and formation of bacterial aggregates on the host surface [18]. Thus superficial liaison occurs due to presence of plant surface proteins known lectins which interact with bacterial exopolysaccharides and receptor present on bacterial surface which recognize signal [nutrients] released by plant.

\section{Colonization}

All plants live in close association with microorganism. Colonization can take the form of many different interactions ranging from symbiosis to parasitism; each interaction affects plant fitness differently. Rhizosphere and phyllosphere is the environment where bacteria colonize. The surface of the aerial portion of the plant known phyllosphere. The phyllosphere of terrestrial plants provides one of the most important niches for microbial Inhabitation. The phyllosphere comprises both the surface and interior of a leaf. Phyllosphere is exposed to rapid and frequent changes in humidity, temperature, UV irradiation, and moisture. Moisture can influence nutrient concentrations and osmolarity. This environment regarded as hostile to microorganisms [21, 22, and 23]. Colonization on phyllosphere is of two types epiphytic and endophytic. In Epiphytic colonization microbes colonize on surfaces of plants .Nutrients on the leaf surfaces are much more limited and spatially heterogeneous, mostly leaked out from the apoplast through natural surface openings and wounds. Numerous microbes, both pathogenic and saprophytic, can survive and even proliferate to various degrees as epiphytes on the plant surface without causing disease. Strict epiphytes complete their life cycles on the surface of plants and generally do not [or are unable to] colonize the leaf apoplast. Microbial inhabitants of the phyllosphere include many different genera of bacteria, yeasts, filamentous fungi, algae, and, less frequently, protozoa and nematodes [23]. Bacteria, especially Erwinia [Pantoea] and Pseudomonas syringae spp., are the most abundantly colonize on the phyllosphere [22, 23]. Availability of carbon containing nutrients like simple sugar [glucose, fructose, and sucrose] on surface of leaves \& stem are the major determinants responsible for epiphytic colonization. These nutrients simply leach from the plant interiors, mostly from sites of injury or from glandular trichomes [24]. Thus these sites are the most heavily populated areas of the plant surface [23, 25, 27, and 28] which results in epiphytic colonization. In Endophythic colonization microbes occupy spaces within plant tissues. The leaf interior is composed mostly of mesophyll cells, in which the bulk of photosynthate is made; some vascular tissues [veins]; and a large, air-filled intercellular space [apoplast] between mesophyll cells. Because of its close proximity to mesophyll cells, the leaf apoplast is thought to contain abundant nutrients. The interior portions of leaves provide more suitable environment because different conditions like humidity is carefully controlled within leaf tissues, due to a waxy cuticle on the plant surface which minimizes water loss. Leaf epidermis contains stomata [small openings], which allow the exchange of carbon dioxide and oxygen. Stomata are the main route by which excess water is lost from the plant; however, they can be closed during periods of dryness to conserve water. When stomata are open, they provide access to the intercellular spaces within leaves and serve as an important entry point for many bacteria $[28,29]$ which leads to endophytic colonization. Roots and Rhizosphere [the zone surrounding root] are readily colonized by microbes [30, 31]. Plant roots harbor a large diversity of microorganisms that have an essential role in ecosystem functioning. The rhizosphere generally provides more protection to environmental conditions like desiccation, temperature, and light stress than the phyllosphere. Sources of carbon and minerals are more abundant in the rhizosphere [30, 32, and 20]. Plants exude high levels of nutrients from their roots, often $20 \%$ of all fixed carbon [19]. Low molecular weight root exudates include Amino acids, organic acids, sugars, aromatics, and various other secondary metabolites comprise whereas high molecular-weight exudates include polysaccharides and proteins [19]. This complex mixture of organic compounds is responsible for larger numbers of microbes in the rhizosphere than in the nearby bulk soil, where the microbial community is carbon limited. This phenomenon is referred to as the "rhizosphere effect" [30]. 


\section{Ecology and Molecular Evolution}

Ecology is the branch of biology dealing with the relations of organisms to one another and to their physical surroundings. All compatible plantmicrobe interactions are not necessarily harmful to the plant. Number of fungi exists in nature that can establish a symbiotic interaction which is mutually beneficial to pathogen as well as to host [33]. Many symbiotic interactions create a niche where the microbe provides the plant with extra nutrients or growth stimulators, or suppresses disease, and in turn, the plant provides a suitable habitat and photosynthates for the microbe. One example of successful symbionts is arbuscular mycorrhizal fungi that mobilize minerals from the soil in exchange for carbon nutrients provided by the plant. There is certain soil borne microorganism which does not live in symbiotic association with plant but interfere with the ability of specific pathogens to infect plants. Such soil borne microorganism contributes to plant health [34]. Such complex microbe-pathogen-plant interactions are difficult to dissect at a molecular level but they are essential for the development of effective biological control strategies [35]. Rhizosphere and phyllosphere is the environment for bacteria to colonize. Distribution of physicochemical factors that is relevant for the microbes inhabiting the plant-associated environments. The physicochemical factor include UV irradiation, temperature, water potential, and iron availability on surfaces of leaves $[51,47,48,49]$ and carbon, phosphate, nitrogen, iron, and oxygen availability in the soil $[50,41,42,43]$. A high-level heterogeneity of apparent sucrose availability on surfaces of leaves allow growth of Pantoea agglomerans [previously known as Erwinia herbicola] [44]. The cells found to be not randomly dispersed across the leaf surface but instead localized to sites which likely to release these nutrients [sucrose]. The sites include stomata, trichomes, veins, and various crevices that are more likely to retain water [45]. Plant roots harbor a large diversity of microorganisms that have an essential role in ecosystem functioning. Tryptophan is found to be most abundant in soil around roots 12 to $16 \mathrm{~cm}$ from the tip, while sucrose is most abundant in soil near the root tip [46]. High sucrose availability at the root tip is thought to be caused by its leakage from the immature, rapidly growing root tissues [44]. Sites having the highest apparent sucrose or tryptophan exudation are the most heavily colonized parts of the root. Plants can also effectively protect themselves against pathogen attack through action of nonspecific resistance mechanisms that are not mediated by $R$ genes [gene which involved in resistance against microbial infection]. For example, the plant environment may be incompatible for a microbe to thrive, or the pathogen may induce a broad spectrum of defense responses that combat the infection. Often such impediments can be major factors in a phenomenon recognized as non-host resistance that places severe restrictions on the host range for a pathogen [36]. Broadspectrum defenses include physical barriers [38], activation of defenserelated proteins [36], or induction of viral RNAdegrading systems [37]. Plants also produce secondary metabolites and other natural products that can confer disease resistance [39]. Systemic acquired resistance is a nonspecific protective mechanism that can be activated when plants are challenged with a pathogen [40].One of the fascinating but controversial processes in plant ecology is the allelopathy which involves mediation of competitive interactions among plants by plant-released metabolites. Molecular evolution is the process of evolution at the level of DNA, RNA and Proteins. Molecular evolution involves various topics like evolution of enzyme function; nucleic acid divergence can be use as molecular clock to study species divergence and origin of junk DNA or non functional DNA. Various events like mutation, changes in allele frequency, gene duplication play important role in emergence of novel gene function. Change in allele frequency occurs due to genetic drift, gene flow, natural selection, sexual selection etc. Driving force behind molecular evolution can be explained by various hypotheses like selectionist's hypotheses [107], Neutralists hypotheses [108] and Mutationists hypotheses [109].

\section{Metabolic Switches}

Plant-Released Sugars alter gene expression. These sugars induce the expression of genes required for their uptake as well as catabolism. The sugar binding protein ChvE of A.tumefaciens play important a role in chemotaxis, in addition to that it is found to be involved in the uptake of glucose and galactose. The chvE gene is part of an operon and it is transcriptionally induced by these monosaccharides [52]. Both glucose and galactose are components of plant-cell wall polysaccharides and are presumably exuded from plants. Induction of the operon is mediated by the product of the divergently transcribed gene gbpR, encoding a LysR-type regulator [73]. In Sinorhizobium meliloti, the melA gene is required for utilization of a-galactosides, and its transcription is induced by $\alpha$-galactosides [53, 54]. Bacteria show high level of melA gene expression in the areas around zones of lateral root initiation and around roots hairs but not around root tips. Other plant root exudates like vitamins, choline, stachydrine, trigonelline, and homoserine can also be used by different species of rhizobia [55-58]. Environmental acidity is a host-associated signal helps in detection of plant host by $A$. tumefaciens. Apoplastic fluids in leaf tissues, as well as the soil adjacent to plant roots, 
are generally acidic, with $\mathrm{pH}$ values between 5 and 6.5 [59]. The $A$. tumefaciens has twocomponent system known ChvG-Chvl which regulates the expression of several unlinked acidinducible genes, and ChvG found to be a global sensory protein that can directly or indirectly sense extracellular acidity [60]. Development of a rhizobium and plant symbiosis is a complex process. It involves a highly coordinated exchange of signals between the plant and the bacteria and leads to a gradual and coordinated differentiation and adjustment of physiology and metabolism in both partners $[61,62,63,68]$.The key event in nodule formation is the synthesis of small molecules called Nod factors [also known as lipo-chito-oligosaccharides] and its release by the bacteria $[65,67,70]$. Detection of Nod factors by a legume host trigger nodule formation Nod factor also induces major developmental changes in the plant, which are required for entry of the rhizobia into the host [64, 65, and 66]. The tip of a root hair, to which rhizobia are bound, curls back on itself, trapping the bacteria within a pocket, from which they are taken up into a plant made intracellular-infection thread. Nod factors also induce cell division and gene expression in the root cortex and pericycle, where they initiate development of the nodule [65, 69, 71, and 72]. Each Rhizobium species therefore produces a different set of Nod factors, which play a critical role in host specificity [67]. Like this with respect to particular signal expression of specific gene takes place in plant as well as in bacteria. This leads to change in metabolic activity which is also called as metabolic switches. Plants as members of complex communities. Plants interact with attackers, such as microbial pathogens and herbivorous arthropods [red] and beneficial organisms, such as rhizobacteria, mycorrhizal fungi, carnivorous arthropods and pollinators [green]. The signaling networks that are activated by the plant in response to its friends and foes overlap, indicating that the regulation of the adaptive response of the plant is finely balanced between protection against aggressors and acquisition of benefits.

\section{Lateral Gene Transfer}

Lateral gene transfer can introduce genes with novel functions into genomes or replace genes with functionally similar orthologs or paralogs. Lateral gene transfer [LGT] is a significant evolutionary mechanism in prokaryotic genome evolution. Indeed, it may be the most important mechanism for evolutionary innovation in Eubacteria and Archaea [85, 86]. The origin of land plants was a key event in the history of life on our planet since it played a fundamental role in the evolution of modern terrestrial ecosystems. The contribution of bacteria to eukaryotic innovations is considered important, but remains poorly explored. The lateral gene transfer from soil bacteria plays an important role in the emergence of key metabolic pathways such as that of phenylpropanoids, and therefore in the path leading to land colonization by plants and their subsequent evolution [87]. The few functional characterizations of soil bacterial PAL [production of secondary metabolites with powerful antimicrobial activity or production of pigments] suggest that the initial advantage of this laterally acquired PAL in the ancestor of land plants might have been either defense against an already developed microbial community and/or protection against UV. Terrestrial environment present earlier were harsh. The ancestor of land plants, which conquered emerged lands had to face important stresses including desiccation, UV radiation [not anymore shielded by water], as well as attack by already diversified microbial soil communities [88, 89]. This drove a number of key adaptations, including the emergence of specialized secondary metabolic pathways. Among them, the phenylpropanoid pathway was crucial. It is in fact a ubiquitous and specific trait of land plants, and provides vital compounds such as lignin essential for vascularization [xylem] and stem rigidity out of water, and flavonoids essential for reproductive biology [flower and fruit colors], protection against UV [pigments] and microbial attack [phytoalexins], and plant-microbe interaction [flavonoids] $[74,75]$. The initial physiological advantage of phenolic compounds is not clear. In fact, flavonoids are not thought to have been immediately effective as UV protection before the emergence of complex structures allowing for their accumulation in large quantities, and it has been proposed that they were initially used as internal signaling molecules [77]. Lignin-like polymers have been identified in the cell walls of the charalean alga Nitella and in bryophytes [mosses, liverworts, and hornworts], early branching lineages of land plants that do not harbor a developed vascular system such as that found in Tracheophytes [Ferns, Gymnosperms and Angiosperms] [78]. Because these lignin monomers in non vascular plants do not fulfill structural functions it has been proposed that may principally serve as a defense mechanism against microorganisms or UV radiation [78]. To date, there is no evidence for the presence of a full phenylpropanoid metabolism in organisms other than land plants, although some bacteria and fungi harbor homologues of a few enzymes of the pathway $[79,80]$. The phenylpropanoid pathway. During early colonization of emerged environments by pioneer land plant ancestors, beneficial associations with fungi and soil bacteria were likely crucial. In particular, it is known that $\mathrm{N} 2$ fixing cyanobacteria formed symbioses with early fungal lineages [lichen-like or endocytobiotic Symbioses, such as those between the glomeromycotan Geosiphon 
pyriformis and the cyanobacterium Nostoc [76]] as well as with land plants, and that fungi [Glomeromycota] Started arbuscular-mycorrhizal [AM] symbioses with the first land plants [76, 81, 82, 83, and 84]. The peculiar distribution and phylogeny of plant PAL suggests a plausible scenario for its origin. PAL emerged in bacteria, likely with an antimicrobial role; a member of an early fungal lineage [i.e. at least before the divergence of Dikarya] obtained a PAL via lateral gene transfer from a bacterium [possibly a Nostocale or another soil bacterium through an early symbiosis][76].This fungal PAL was transferred to an ancestor of land plants via an ancient AM symbiosis, where it paved the way for the development of the phenylpropanoid pathway, and the radiation of plants on terrestrial environments. Lateral gene transfer helps in development of various secondary metabolite pathways in plant which make plant to survive in stress condition also helps to protect them from harmful UV radiation. Lateral gene transfer in plants from bacteria helps plant to conquer competitive environment and thus their survival.

\section{Species Delineation and Biogeography}

Soils constitute a primordial compartment of terrestrial ecosystems. In all biogeochemical cycles soils play a fundamental role. Soil processes depend on physical and chemical parameters [climate, parent rock] but also depend on many soil organisms such as bacteria, fungus, mesofauna [collembola, mite], macrofauna [earthworm, termite, ant, insect larvae, millipede...] and plants. In order to study the interactions between these organisms and between these organisms and their physical environment has required the development of a whole scientific domain, soil ecology. $[104,105]$ Besides the desire to increase ecological knowledge, the importance of the involved applied issues [soil fertility, soils as a carbon sink...etc] has strongly fostered the development of soil ecology as proved by the existence of many specialized journals. The field is currently making wide progresses. For example, many recent studies reveal new mechanisms that could deeply influence soil fertility, competition between plants or ecosystem reaction to global change. [106].

\section{Molecular Co-Evolution}

The evolution that occurs among organisms without genetic exchange is called as molecular co-evolution. It involves reciprocal selective interaction between two groups of organism e.g. Plants \& microbes, large organisms \& their symbionts. The process of co-evolution resulting from the reciprocal selection pressure exerted by the plant and the pathogen is widely considered to be a potential mechanism which acts on resistance and virulence diversity in wild populations [101-103]. Co evolution between plants and their enemies involves many interactions at molecular level. In the legumerhizobium mutualism, plants provide rhizobia with carbon and shelter inside of root nodules, while rhizobia provide plant available nitrogen $[\mathrm{N}]$ that they have converted [fixed] from atmospheric N2 [91]. Data from both agricultural systems [92, 93], as well as a few non-domesticated systems [94, $95,96]$, reveal that plant biomass and $\mathrm{N}$ content vary when plants are grown in symbiosis with different rhizobium strains. In other words, there exists genetic variation for the benefits plants receive from symbiosis with rhizobia. Moreover, variation exists among rhizobium strains for the capacity to form nodules with different plant genotypes or species $[93,96]$. Despite the negative economic consequences of plant diseases and benefits of symbiotic interactions, most plants resist infection by most microbes. This phenomenon has generated variations on the same fundamental question ever because of which scientists started studying plant-infecting microbes: Plant disease resistance often results from the presence of a specific resistance [R] gene in the plant and a corresponding avirulence gene in the pathogen. $R$ genes obeying this gene for- gene [GFG] model [97] have been identified in cultivated as well as wild plants $[98,99,100]$. This sets off a hypersensitive response [HR] that culminates in rapid cell death around the site of infection and thus effectively prevents further spread of the pathogen.In the co evolution of host-microbe interactions, pathogens acquired the ability to deliver effector proteins to the plant cell to suppress $\mathrm{PTI}$ [The primary immune response is referred to as PAMP-triggered immunity $[\mathrm{PTI}]$, allowing pathogen growth and disease. In response to the delivery of pathogen effector proteins, plants acquired surveillance proteins [R proteins] to either directly or indirectly monitor the presence of the pathogen effector proteins [90].

\section{Conclusion}

In the past 20 years, numerous studies have shown that plant-associated bacteria can detect various host-released chemicals, to which they respond in ways that allow them to colonize their host. In this review, we described such plant released signals, the way they are recognized, and the way they trigger the appropriate responses in the bacteria. Many aspects of these processes like colonization, molecular co evolution, ecology \& biogeography, lateral gene transfer etc. are understood in some detail. However, as each new insight opens new questions, a lot of exciting work is waiting to be done. 


\section{References}

[1] Willems A., Collins M. D. (1993) Int. J. Syst. Bacteriology, 43:305-313.

[2] Young J. M., Kuykendall L. D., MartinezRomero E., Kerr A. and Sawada H. (2001) Int. J. Syst. Evol. Microbiology, $51: 89-103$.

[3] Capela D., et al., (2001) Proc. Natl. Acad. Sci. USA, 98:9877-9882.

[4] Kaneko T., et al., (2000) DNA Res., 7:331338.

[5] Kaneko T., et al., (2002) DNA Res., 9:189197.

[6] Galibert F., et al., (2001) Science, 293:668672.

[7] Ashby A. M., Watson M. D., Loake G. J. and Shaw C. H. (1988) J. Bacteriol., 170:4181-4187.

[8] Caetano-Anolles G., Cristestes D. K. and Bauer W. D. (1988) J.Bacteriol., 170:3164-3169.

[9] Hawes M. C., and Smith L. Y. (1989) J. Bacteriol., 171:5668-5671.

[10] Parke D., Rivelli M. and Ornston L. N. (1985) J. Bacteriology, 163:417-422.

[11] Hirsch A. M. (1999) Curr. Opin. Plant Biol., 2:320-326.

[12] Ridge R. W., Kim R. and Yoshida F. (1998) Protoplasm, 202:84-90.

[13] Rudiger H. and Gabius H. J. (2001) Glycoconj. J., 18:589-613.

[14] Matthysse A. G. and Kijne J. W. (1998) Kluwer Academic Publishers, Dordrecht, the Netherland, 235-249.

[15] Cangelosi G. A., Ankenbauer R. G. and Nester E. W. (1990) Proc. Natl. Acad. Sci. USA, 87:6708- 6712.

[16] Lelpi L., Dylan T., Ditta G. S., Helinski D. R. and Stanfield S. W. (1990) J. Biol. Chem., 265:2843-2851.

[17] Stanfield S. W., Lelpi L., O'Brochta D., Helinski D. R. and Ditta G. S. (1988) J. Bacteriol., 170:3523-3530.

[18] Matthysse A., Role G. S. (1983) J. Bacteriol., 154:906-915.

[19] Marschner H. (1995) 2nd ed. Academic Press, Ltd., London, United Kingdom.

[20] Walker T. S., Bais H. P., Grotewold E. and Vivanco J. M. (2003) Plant Physiol., 132:44-51.

[21] Lindow S. E. and Brandl M. T. (2003) Appl. Environ. Microbiol., 69:1875-1883.

[22] Hirano S. S. and Upper C. D. (2000) Microbiol.Mol.Biol.Rev,64:624-653.

[23] Andrews J. H. and Harris R. F. (2000) Annu. Rev. Phytopathol., 38:145-180.

[24] Tukey H. B (1970) Annu. Rev. Plant Physiol., 21:305-324.

[25] Davis C. L. and Brlansky R. H. (1991) Appl. Environ. Microbiol.,57:3052-3055.

[26] Mercier J. and Lindow S. E. (2000) Appl. Environ. Microbiol., 66:369-374.
[27] Wilson M., Hirano S. S. and Lindow S. E. (1999) Appl. Environ. Microbiol., 65: 1435-1443.

[28] Beattie G. A. and Lindow S. E. (1999) Phytopathology, 89:353-359.

[29] Beattie G. A. and Lindow S. E. (1995) Annu. Rev. Phytopathol., 33:145-172.

[30] Bolton H., Fredrikson J. K. and Elliot L. E. (1992) In F. B. Metting, Jr. (ed.), Soil microbial ecology. Marcel Dekker, Inc., New York, N.Y., 27-63.

[31] Bowen G. D. and Rovira A. D. (1999) Adv. Agron., 66:1-102.

[32] Curl E. A. and Truelove B. (1986) SpringerVerlag, New York, N.Y

[33] Smith K.P. and Goodman R.M. (1999) Annu Rev Phytopathol., 37:473-491.

[34] Handelsman J. and Stabb E.V. (1996) Plant Cell ,8:1855-1869.

[35] Baek J.M., Howell C.R. and Kenerley C.M. (1999) Current Genet., 35:41-50.

[36] Heath M.C. (2000) Current Opin. Plant Biol., 3:315-319.

[37] Waterhouse P.M., Wang M.B. and Lough T. (2001) Nature, 411:834-842.

[38] Walton J.D. (1994) Plant Physiology, 104:1113-1118.

[39] Dixon R.A. (2001) Nature, 411:843-847.

[40] Sticher L., Mauch-Mani B. and Metraux J.P. (1997) Annu Rev Phytopathology ,35:235-270.

[41] Jensen L. E. and Nybroe O. (1999) Appl. Environ. Microbiol. 65:4320-4328.

[42] Koch B., Worm J., Jensen L. E., Hojberg O. and Nybroe O. (2001) Appl. Environ. Microbiol., 67:3363-3370.

[43] Kragelund L., Hosbond C. and Nybroe O. (1997) Appl. Environ. Microbiol. , 63:4920-4928.

[44] Jaeger C. H., Lindow S. E., Miller S., Clark E. and Firestone M. K. (1999) Appl. Environ. Microbiol., 65:2685-2690.

[45] Wright C. A. and Beattie G. A. (2004) Proc. Natl. Acad. Sci. USA, 101:3269-3274.

[46] Harleen Kaur, Rajwant Kaur, Surinder Kaur, Ian T. Baldwin and Inderjit (2009) University of Delhi, India.

[47] Joyner D. C. and Lindow S. E. (2000) Microbiology, 146:2435-2445.

[48] Kim J. J. and Sundin G. W. (2000) J. Bacteriol. 182:6137-6144.

[49] Ullrich M. S., Schergaut M. , Boch J. and Ullrich B. (2000) Microbiology, 146: 2457-2468.

[50] Hojberg O., Schnider U., Winteler H. V., Sorensen J. and Haas D. (1999) Appl. Environ. Microbiol. 65:4085-4093.

[51] Axtell C. A. and Beattie G. A. (2002) Appl. Environ. Microbiol., 68:4604-4612.

[52] Kemner J. M., Liang X. and Nester E. W. (1997) J. Bacteriol., 179:2452-2458. 
[53] Bringhurst R. M., Cardon Z. G. and Gage D. J. (2001) Proc. Natl. Acad. Sci. USA, 98;4540-4545.

[54] Gage D. J. and Long S. R. (1998) J. Bacteriol, 180:5739-5748.

[55] Boivin C., Barran L. R., Malpica C. A. and Rosenberg C. (1991) J. Bacteriol., 173:2809-2817.

[56] K. E., Sohlenkamp C., Rudder de and Geiger O. (1999) J. Biol. Chem., 274: 20011-20016.

[57] Phillips D. A., Sande E. S., Vriezen J. A. C., de Bruijn F. J., Le Rudulier D. and Joseph C. M. (1998) Appl. Environ. Microbiol., 64:3954-3960.

[58] Streit W. R., Joseph C. M. and Phillips D. A. (1996) Mol. Plant-Microbe Interact., 9:330-338.

[59] Grignon C., and Sentenac H. (1991) Annu. Rev. Plant Physiol. Plant Mol. Biol., 42:103-128.

[60] Li. L. P., Jia Y. H., Hou Q. M., Charles T. C., Nester E. W. and Pan S. Q. (2002) Proc. Natl. Acad. Sci. USA, 99:1236912374.

[61] Perret X., Staehelin C. and Broughton W. J. (2000) Microbiol. Mol. Biol. Rev., 64:180-201.

[62] Schultze M. and Kondorosi A. (1998) Annu. Rev. Genet., 32, 33-57.

[63] Spaink H. P (2000) Annu. Rev. Microbiol., 54:257-288.

[64] Downie J. A. and Walker S. A. (1999) Curr. Opin. Plant Biol., 2:483-489.

[65] Geurts R. and Bisseling T. (2002) Plant Cell, 14(Suppl.):S239-S249.

[66] Stougaard J. (2000) Plant Physiol., 124:531-540.

[67] Cullimore J. V., Ranjeva R. and Bono J. J. (2001) Trends Plant Sci., 6:24-30.

[68] Bladergroen M. R. and Spaink H. P. (1998) Curr. Opin. Plant Biol., 1, 353-359.

[69] Horvath B., Heidstra R., Lados M., Moerman M., Spaink H. P., Prome J. C., Vankammen A. and Bisseling T. (1993) Plant J., 4,727-733.

[70] Long S. R. (1996) Plant Cell, 8, 1885-1898.

[71] Spaink H. P. (1996) Crit. Rev. Plant Sci., 15, 559-582.

[72] Truchet G., Roche P., Lerouge P., Vasse J., Camut S., Debilly F., Prome J. C. and Denarie J. (1991) Nature, 351,670-673.

[73] Doty S. L., Chang M. and Nester E. W. (1993) J. Bacteriol., 175, 7880-7886.

[74] Ferrer J.L., Austin M.B., Stewart C. Jr., Noel J.P. (2008) Plant Physiol Biochem, 46,356-370.

[75] Dixon R.A., Achnine L., Kota P., Liu C.J., Reddy M.S.S. and Liangjiang Wang L. (2002) Mol Plant Pathology, 3,371-390.

[76] Parniske M. (2008) Nature Reviews Microbiology, 6,763-771.
[77] Stafford H.A. (1991) Plant Physiol., 96,680685.

[78] Ligrone R., Carafa A., Duckett J.G., Renzaglia K.S., Ruel K. (2008) Plant Systematic and Evolution, 270,257-272.

[79] Moore B.S., Hertweck C., Hopke J.N., Izumikawa M., Kalaitzis J.A., Nilsen G., O'Hare T., Piel J., Shipley P.R., Xiang X.L., Austin M.B., Noel J.P.(2002) J Nat Prod., 65,1956-1962.

[80] Seshime Y., Juvvadi P.R., Fujii I. and Kitamoto K. (2005) Biochem Biophys Res Commun, 337(3), 747-751.

[81] Brundeztt M.C. (2002) New Phytologist, $154,275-304$

[82] Raven J.A. (2002) Biology and Environment: Proceedings of the Royal Irish Academy, 1, 3-6.

[83] Yuan X., Xiao S. and Taylor T.N. (2005) Science, 308, 1017-1020.

[84] Selosse M.A. and Le Tacon F. (1998) Tree, $13,15-20$

[85] Doolittle W.F. (1999) Science, 284, 21242129.

[86] Ochman H., Lawrence J.G. and Groisman E.A. (2000) Nature, 405,299- 304.

[87] Giovanni Emiliani, Marco Fondi, Renato Fani and Simonetta Gribaldo (2009) $A$ horizontal gene transfer at the origin of phenylpropanoid metabolism: a key adaptation of plants to land.

[88] Kenrick P., Crane P.R. (1997) Nature, 389, 33-39.

[89] Waters E.R. (2003) Mol Phylogenet Evol, 29(3), 456-463.

[90] Corné M.J. Pieterse and Marcel Dicke (2007) Plant interactions with microbes and insects: from molecular mechanisms to ecology.

[91] Vance C. P. (2002) In Plant roots: the hidden half (Eds Y. Waisel, A. Eshel \& U. Kafkafi) New York, NY: Marcel Dekker, Inc, 839-868.

[92] Miller R. W. and Sirois J. C. (1982) Appl. Environ. Microbiol., 43,764-768.

[93] Robinson K. O., Beyene D. A., van Berkum P., Knight- Mason R. and Bhardwaj $\mathrm{H}$. L. (2000) Plant Sci., 159, 257-264.

[94] Parker M. A. (1995) Ecology, 76, 15251535.

[95] Burdon J. J., Gibson A. H., Searle S. D., Woods M. J. and Brockwell J. (1999) J. Appl. Ecol., 36,398-408.

[96] Mhadhbi H., Jebara M., Limam F., Huguet T. and Aouani M. E (2005) Physiol. Plant, 124,4-11.

[97] Flor H. (1971) Annu. Rev. Phytopathol., 9,275-296.

[98] Barrett J., Rollinson A. D. and Anderson R. M. (1985) eds. Academic, New York. Ecology and Genetics of Host-Parasite Interactions, 215-225. 
[99] Burdon J. J. (1994) Evolution, 48, 15641575.

[100] Clarke D. D. (1997) The Gene-for-Gene Relationship in Plant-Parasite Interactions. I. R. Crute, E. B. Holub, and J. J. Burdon, eds. CAB Int., Wallingford, UK., 231-243.

[101] Thompson J. N. and Burdon J. J (1992) Nature, 360,121-125.

[102] Thrall P. H. and Burdon J. J. (1997) J. Ecol., 85,743-753.

[103] Simms E. L. (1996) Bioscience , 46,136.

[104] Bonkowski M. (2004) New Phytol 162: 617631.

[105] Hodge A., Campbell C.D., Fitter A.H. (2001) Nature, 413, 297-299.

[106] Goddard M.R., Bradford M.A. (2003) Ecol Lett .,6:594-598.

[107] Graur D. and Li W.H. (2000) Fundamentals of molecular evolution. Sinauer.

[108] Kimura M. (1983) Cambridge University Press, Cambridge. ISBN 0-521-231094.

[109] Nei M. (2005) Molecular Biology and Evolution 22(12): 2318-2342. 